\title{
A factorial cluster-randomised controlled trial combining home-environmental and early child development interventions to improve child health and development: rationale, trial design and baseline findings
}

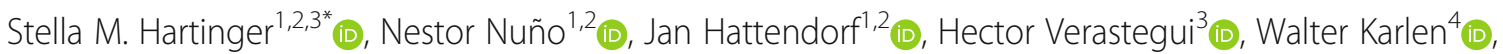
Mariela Ortiz ${ }^{5}$ (D) and Daniel Mäusezahl ${ }^{1,2}$ (D)

\begin{abstract}
Background: Exposure to unhealthy environments and inadequate child stimulation are main risk factors that affect children's health and wellbeing in low- and middle-income countries. Interventions that simultaneously address several risk factors at the household level have great potential to reduce these negative effects. We present the design and baseline findings of a cluster-randomised controlled trial to evaluate the impact of an integrated home-environmental intervention package and an early child development programme to improve diarrhoea, acute respiratory infections and childhood developmental outcomes in children under 36 months of age living in resource-limited rural Andean Peru.

Methods: We collected baseline data on children's developmental performance, health status and demography as well as microbial contamination in drinking water. In a sub-sample of households, we measured indoor kitchen 24-h air concentration levels of carbon monoxide (CO) and fine particulate matter $\left(\mathrm{PM}_{2.5}\right)$ and $\mathrm{CO}$ for personal exposure.

Results: We recruited and randomised 317 children from 40 community-clusters to four study arms. At baseline, all arms had similar health and demographic characteristics, and the developmental status of children was comparable between arms. The analysis revealed that more than $25 \%$ of mothers completed primary education, a large proportion of children were stunted and diarrhoea prevalence was above $18 \%$. Fifty-two percent of drinking water samples tested positive for thermo-tolerant coliforms and the occurrence of E.coli was evenly distributed between arms. The mean levels of kitchen $\mathrm{PM}_{2.5}$ and $\mathrm{CO}$ concentrations were $213 \mu \mathrm{g} / \mathrm{m}^{3}$ and $4.8 \mathrm{ppm}$, respectively.

(Continued on next page)
\end{abstract}

* Correspondence: stella.hartinger.p@upch.pe

'Department of Epidemiology \& Public Health, Swiss Tropical and Public

Health Institute, Basel, Switzerland

${ }^{2}$ University of Basel, Basel, Switzerland

Full list of author information is available at the end of the article

(c) The Author(s). 2020 Open Access This article is licensed under a Creative Commons Attribution 4.0 International License, which permits use, sharing, adaptation, distribution and reproduction in any medium or format, as long as you give appropriate credit to the original author(s) and the source, provide a link to the Creative Commons licence, and indicate if changes were made. The images or other third party material in this article are included in the article's Creative Commons licence, unless indicated otherwise in a credit line to the material. If material is not included in the article's Creative Commons licence and your intended use is not permitted by statutory regulation or exceeds the permitted use, you will need to obtain permission directly from the copyright holder. To view a copy of this licence, visit http://creativecommons.org/licenses/by/4.0/ The Creative Commons Public Domain Dedication waiver (http://creativecommons.org/publicdomain/zero/1.0/) applies to the data made available in this article, unless otherwise stated in a credit line to the data. 
(Continued from previous page)

Conclusions: The trial arms are balanced with respect to most baseline characteristics, such as household air and water pollution, and child development. These results ensure the possible estimation of the trial effectiveness. This trial will yield valuable information for assessing synergic, rational and cost-effective benefits of the combination of home-based interventions.

Trial Registry: ISRCTN-26548981.

Keywords: Cluster-randomised trial, Integrated home-based interventions, Early child development, Diarrhoea, Respiratory infections, Kitchen hygiene, Household air pollution, Household water treatment, Improved biomass cookstoves, Peru

\section{Background}

Children in low- and middle-income countries are frequently exposed to cumulative health and developmental risks often rooted in unhealthy environments [1], with household air pollution (HAP) and water, sanitation and hygiene (WASH) being the main risk factors [2]. Unfortunately, $40 \%$ of the world population still relies on solid fuels for cooking [3], 11\% does not have access to an unimproved drinking water source and 36\% lacks sanitation [4]. These risk factors disproportionally target the poor and vulnerable increasing the burden of communicable (acute respiratory infections [5], pneumonia [6], diarrhoea $[7,8]$ ) and non-communicable diseases (COPD [9], adverse birth outcomes [10], malnutrition $[11,12])$ in these populations. Overall, HAP accounts for 3.8 million deaths [13] and WASH for 0.8 million deaths worldwide [12]. Child developmental outcomes such as cognitive deficits, neurodevelopment affectation [14, 15], sensorimotor and socio-emotional development [16] have been linked to unhealthy environments, especially if exposure occurs during the first years of life $[17,18]$. Early child development (ECD) generates opportunities that shape children's lifelong health and developmental status [18]; however, around two hundred million children worldwide are not reaching their full cognitive potential [14], increasing the in equity between populations, and promoting lifetime adverse consequences that impact the wellbeing of future generations $[15,19]$. Hence, improving access to basic services through structural household improvements such as latrines, running water in-house or ventilation-improved cooking devices on the one hand, as well as improving life course determinants at an early age on the other hand are promising interventions to reduce the household burden of disease.

Individual WASH and HAP interventions reduce the burden of disease. A recent systematic review showed that point-of-use filtration and water disinfection interventions reduced the risk of diarrhoea by 53 and $31 \%$ respectively; hygiene education focusing on handwashing with soap resulted in a $27 \%$ reduction [7]. In addition, continuous availability of higher quality water piped to households can also reduce diarrhoea by $75 \%$ [20]. Improved cookstoves (ICS) interventions have also shown impact on HAP exposure reduction [21], improved health $[22,23]$ and wellbeing. ECD interventions enhanced health status [24] and development in children [25].

The improvement of poor health and development requires integrated approaches addressing the underlying social, behavioural risks and household infrastructural determinants at the household level [16, 26]. Multiple studies have demonstrated that low-cost interventions focusing on various health risk factors simultaneously had a synergic effect and increased opportunities for sustained use of them over time [27, 28]. Integrating ECD and home-hygiene interventions is promising as they both target young children within their homes $[29,30]$. The home-based approach enhances the effects of ECD interventions, which could also lead to improvements of children's general health and affection and mothers' mental health [31, 32]. Furthermore, this combination can improve the effectiveness of each intervention alone and reduce the use of material and human resources compared to the implementation of these interventions independently. In this article, we describe the design and baseline results of a cluster-randomised controlled trial seeking to develop an integrated cost-effective home-based package (IHIP) of environmental health and ECD interventions in rural Andean Peru.

\section{Methods}

\section{Setting and subjects}

The trial was conducted in the San Marcos and Cajabamba provinces, Cajamarca region, Andean Peru. We chose the locations based on the coverage of the national ECD programme ("Programa Nacional Cuna Mas" (PNCM)) and on-going relationships with local stakeholders who partook in a previous cluster-randomised controlled trial conducted in the region. The results of our previous research endeavours facilitated the implementation of this new trial ("IHIP2 trial" in the following) $[25,29]$. Both sites were high altitude rural resource-limited locations with chronic malnutrition and illiteracy [33]. The majority of the population 
were small-scale farmers living in 2-3 roomed houses with earthen floors and adobe walls, with traditional stoves or open fires for cooking.

\section{Study design}

We implemented a $2 \times 2$ factorial design trial applying two interventions individually and in combination: i) an environmental health package comprising a certified ICS, kitchen sink and hygiene education (IHIP); and ii) an early child development programme (ECD). This design led to four potential experimental conditions: i) IHIP \& ECD ("IHIP+" in the following), ii) IHIP, iii) ECD and iv) Control. We chose this design because it randomises communities instead of individuals, avoiding contamination between participants.

We enrolled all families complying with the following inclusion criteria: i) had at least one child $<1.5$ years living at the household; ii) used solid fuels as main energy source for cooking/heating; iii) had access to piped water in the yard; iv) did not plan to move within the next 24 months; and iv) did not participate in the PNCM (Additional file 1).

\section{Sample size}

We calculated the sample size using the formula proposed by Hayes \& Bennett for cluster-randomised trials [34], assuming three episodes of diarrhoea per child-year, a $25 \%$ reduction of the incidence compared to the control arm, and a coefficient of variation of 0.2 . With 10 person-years of follow-up in each cluster, we calculated 16 clusters for the intervention and control arm to detect the anticipated reduction of incidence with a power of $80 \%$ at the $5 \%$ two-sided significance level. To account for potential loss to follow-up, we included 40 clusters with an average of 6.5 person-years of follow-up. For the ECD intervention, we used the ECD outcome (percentage of tasks solved above the mean of the study population) of our previous intervention study [25] and assumed 60\% above mean for the intervention and $40 \%$ above mean in the control arm. Using the equivalent formula for proportions, we calculated that 15 clusters for intervention and control with ten children were required. Of note, the trial is sufficiently powered to compare each intervention against the corresponding control arms (i.e. for IHIP arm $1 \& 2$ vs $3 \& 4$ and for ECD arm $1 \& 3$ vs $2 \& 4$ ) but does not allow pair wise comparisons among the four trial arms.

\section{Recruitment}

We carried out a census in 2015 to identify potential communities, children and pregnant women in their second and third trimester in collaboration with the Peruvian Ministry of Health (MINSA). Participants were enrolled between September 2015 and January 2016. If multiple eligible children were found in a household, we selected the youngest child.

\section{Randomisation}

We enrolled 82 eligible communities, which we aggregated into 40 community-clusters because of their partly close proximity to each other. After the enrolment, we allocated the communities into the four study arms using a covariate-based constrained randomisation as proposed by Moulton [35]. Based on geographic distance, we first divided the clusters into 8 strata of 4 clusters each and 1 stratum of 8 clusters. We then generated two million random allocation sequences and selected those for which the maximum difference between arms was i) $\leq 5$ in terms of number of villages; ii) $\leq 10$ for the number of children; iii) median village size (number of households) $\leq 10$; iv) median altitude $\leq 250$; v) proportion of households with a health post in the community $\leq 10 \%$-points; vi) proportion of households with a school within the community $\leq 10 \%$-points; and vii) proportion of households living in villages having an electricity connection $\leq 10 \%$-points. Of the 164 allocation sequences that fulfilled all criteria, one was randomly selected.

\section{Design and implementation of study interventions The IHIP intervention}

The IHIP package was developed to improve unsafe drinking water, hygienic conditions and HAP levels and, consequently, enhance potential effects to reduce diarrhoea and respiratory infections. It was designed using an extended community participatory approach on the needs and preferences of rural Andean populations [28, 36]. To select the ICS model, we consulted communities on their preference regarding three pre-selected ICS between May and July 2015. Forty-eight women were asked to cook with each ICS model for three consecutive days ( 9 in total). Participant women selected the ICS "OPTIMA" model and recommended further modifications before its installation. The modified stove was certified by the Peruvian national industrial certification authority (SENCICO) [37]. To increase availability of water inside the household and convenience in accomplishing household chores (both were expressed needs and voiced at user consultations), prefabricated cement sinks were installed inside the kitchen and connected to the local water supply found in the household yard (between 5 and $20 \mathrm{~m}$ away from the kitchen).

Kitchen sinks and stove parts were purchased locally to increase scalability. Both interventions were implemented between November 2015 and February 2016. Activities of the hygiene education component were carried out continuously (every month) throughout the study; this was done with the aid of a small flip chart. We conveyed three main messages: i) Kitchen hygiene: 
elimination of animal excreta and keeping the kitchen environment clean; ii) Hand washing: of the mother's and child's hands with soap or detergent at key moments during the day (after using the toilets, changing diapers, before preparing the meals and before eating); and iii) household water treatment. We especially promoted boiling, since it is the main HWT endorsed by the health authorities in the area. All other HWT methods were also discussed during the sessions.

\section{Early child development intervention}

The ECD intervention was based on the PNCM [38]. The PNCM was launched in 2012 to improve the cognitive, social and emotional development of infants $<3$ years of age living in poverty. In addition, the programme sought to improve families' knowledge and practices regarding caregiving, and strengthen the bond between mothers and children. The PNCM provides a home-visiting intervention in rural areas ("Acompañamiento a Familias" (AAF)) as opposed to a day-care service in urban settings. The AAF was implemented and evaluated in our trial.

Mother facilitators (MF) were trained women living in the participating communities and conducted weekly play-oriented, semi-structured activities with the participant mothers (or caretakers) and the child. MFs were selected using PNCM guidelines and received a one-day training session and monthly re-trainings. MFs were supervised by a technical assistant team (TA), which mentored and assisted MFs in the planning of the weekly sessions according to the PNCM guidelines. TA team organised group sessions with participant mothers every two months to share experiences, lessons or concerns of the ECD intervention. The TA team received a one-week training session from PNCM experts in the planning and delivery of the ECD sessions. All participating households received a set of age-specific toys to stimulate children's psychomotor and cognitive development every 2 months (six packages in total). These educational materials aimed to foster communicative, socio-emotional and cognitive abilities and to teach mothers how to plays and equip them with ideas for new games for daily interactions with their child.

\section{Primary and secondary outcomes}

\section{Definition of the primary and secondary outcomes}

We assessed childhood diarrhoea and ECD status as primary outcomes. We defined diarrhoea according to the World Health Organization (WHO) standards, as the passing of at least three loose stools within $24 \mathrm{~h}$ [39], and ECD outcomes as an age standardised mean score of psychomotor assessment (including socio-emotional, motor and cognitive skills, and communication abilities) in children $<3$ years of age.
The secondary outcomes included: i) acute respiratory infections (ARI), defined as presence of cough and fever reported by the primary caretaker, according to the WHO standards [40]; ii) severe cases of diarrhoea defined as persistent diarrhoea for more than 14 days or bloody diarrhoea; iii) household carbon monoxide (CO) and particle matter $\left(\mathrm{PM}_{2.5}\right)$ emissions and $\mathrm{CO}$ personal exposure in a sub-sample of 40 participants; iv) presence of E.coli in drinking water samples; and v) compliance linked to the use of the interventions. We assessed compliance with stove and sink use and hygiene through spot check observations, 24-h recall data and direct observations in the sentinel sub-sample. ECD compliance was defined as reported ECD sessions since the last TA's household visit and mother's satisfaction associated with the MFs visits.

\section{Data collection of primary and secondary outcomes}

We carried out active and passive surveillance to collect diarrhoea and ARI morbidity data during the 12-month follow-up. The fieldworker team (FW) visited all households weekly and collected daily and weekly selfreported information from the mother or caretaker about the occurrence of signs and symptoms of child diarrhoea and ARI. The FW was instructed to obtain two measurements of respiratory rates, which increased the specificity for a diagnosis without a loss of sensitivity [41]. To define the severity of the disease, for diarrhoea, we collected additional information on observed blood in the stools. For ARI, we measured respiratory rate, heart rate and oxygen saturation in blood $\left(\mathrm{SpO}_{2}\right)$ with portable pulse oximeters (PPOs) (Masimo $\mathrm{iSpO}_{2} \mathrm{Rx}$ ) and multisite reusable sensors (Masimo M-LNCS YI $\mathrm{SpO}_{2}$ ) connected to tablets (Lenovo Tab 2 A7-10). We used the lambdanative framework [42] to develop a mobile app which provided data entry and real-time feedback on signal quality [43]. Respiratory rate was recorded using the RRate app module [44]. Severely ill children were referred to the local healthcare facility for further evaluation. The FW initially received five-days of training in morbidity data collection with monthly retraining sessions of $2 \mathrm{~h}$. All the surveillance devices and tools were tested on a daily-basis between February and April 2016. In addition, the passive surveillance team (PS) collected health data from our study participants monthly at their local community-based health centres (22 in total). To ensure that they were also collecting $\mathrm{SpO}_{2}$ in each evaluation, we provided PPOs, sensors and tablets to local health centres. During the visits, the PS also trained local health personnel on the maintenance and use of the PPOs. Anthropometric measurements were collected from the participant's clinical records. We assessed stunting and underweight following the 
WHO standards; stunting: height-for-age $\mathrm{z}$-score $<-2$; underweight: weight-for-age z-score $<-2$ ) [45].

The environmental team (EV) collected household air pollution and drinking water samples. The EV received 7 days of initial training and monthly retraining sessions. We collected 24-h kitchen and personal $\mathrm{CO}$ and $\mathrm{PM}_{2.5}$ exposure data. We installed one EL-USB-CO (LACAR Electronics) monitor and one HAP measuring device for indoor use APROVECHO5000 at a one-meter distance from the ICS and at standard breathing height $(1.5 \mathrm{~m})$. To measure personal exposure, mothers were carrying a vest equipped with one EL-USB-CO (LASCAR Electronics) monitor and one micro personal aerosol exposure monitor (RTIINTERNATIONAL). We asked mothers to wear the vest for $24 \mathrm{~h}$ only taking them off for sleeping and personal hygiene.

We obtained drinking water samples from the child's main drinking source, and then transported them to the field station's laboratory in San Marcos, in cooled thermal bags. At the laboratory, the samples were analysed for thermotolerant (faecal) coliforms using a membrane-filtration method from the Oxfam DelAgua water testing kit [46]. All yellow colonies forming units were considered positive for E.coli growth. These were then collected and placed in transportation vials media and sent to Lima for further phenotypic and genotypic identification and antibiotic resistance testing.

HAP data were obtained from the sentinel sub-sample five times (before ICS installation, three times during follow-up, and at the end of study). Water samples were collected at baseline and end of study for all study participants and in the sentinel sub-sample three additional times over the follow-up.

To assess ECD status, the TA carried out an assessment using the nationally validated Peruvian Infant Development Scale (ESDI) tool [38] at baseline and end of study. The TA received 1 week of training from PNCM experts. At the end of study, a group of specialized psychologists also conducted the Bayley Scales of Infant and Toddler Development (BSID) [47] instrument for comparability.

Finally, the capacity building team (CBT) was responsible for re-training participants on hygiene, handwashing, boiling practices and ICS maintenance. The CBT conducted monthly reinforcement visits and collected data on the IHIP intervention condition. A local ICS constructor was hired to supported additional maintenance of the intervention on demand. During their visits, the FW, CBT and TA conducted regular spot check observations and collected maternal reports on the usage and quality of the interventions as well as household and environmental hygiene.

\section{Socio-economic survey}

The FW implemented a socio-economic questionnaire at baseline and end of study. The objective was to assess household demographics, education and economic characteristics, general stove use and household water management. We conducted the baseline assessment between September 2015 and February 2016. The FW received 1 week of training.

\section{Data quality management}

The field coordinator team revised information collected on a daily basis to reduce the chance of missing data. They also trained the field staff, double-checked questionnaires and conducted regular household quality visits. Ten percent of all data collected in the trial was double entered to ensure data quality. To reduce the possibility of courtesy bias, household data collection routes of FW were changed every 2 months. The data integrity of physiological data obtained from the PPO and RRate were automatically assessed using validated computer algorithms [44].

\section{Data analysis}

The data was entered in the Census and Survey Processing System (CS Pro 6.3) and data files were exported to Stata 15 Statistical software (STATA CORP, College Station, Texas, USA) for analysis. We performed a descriptive analysis (means, percentages) for the main household characteristic and for the health characteristics we calculates prevalence and proportions.

\section{Results \\ Enrolment}

From the screening census, we identified 102 communities with 574 potential children. During enrolment we found that 237 families were no longer eligible because i) they participated in another social programme $(N=$ 167); ii) they did not fulfil the inclusion criteria $(N=34)$, or iii) they rejected participation $(N=36)$. We reenrolled between January and February 2016 because 28 children were not available or rejected to participate in the project at the beginning of the follow-up. In total, 317 households in 10 clusters per arm participated in the trial (Fig. 1).

\section{Baseline characteristics}

Baseline analysis included the demographic and health characteristics, the household drinking water quality and levels of ECD indicators for each participant. We measured household and personal air pollution concentrations in the sentinel sub-sample. 


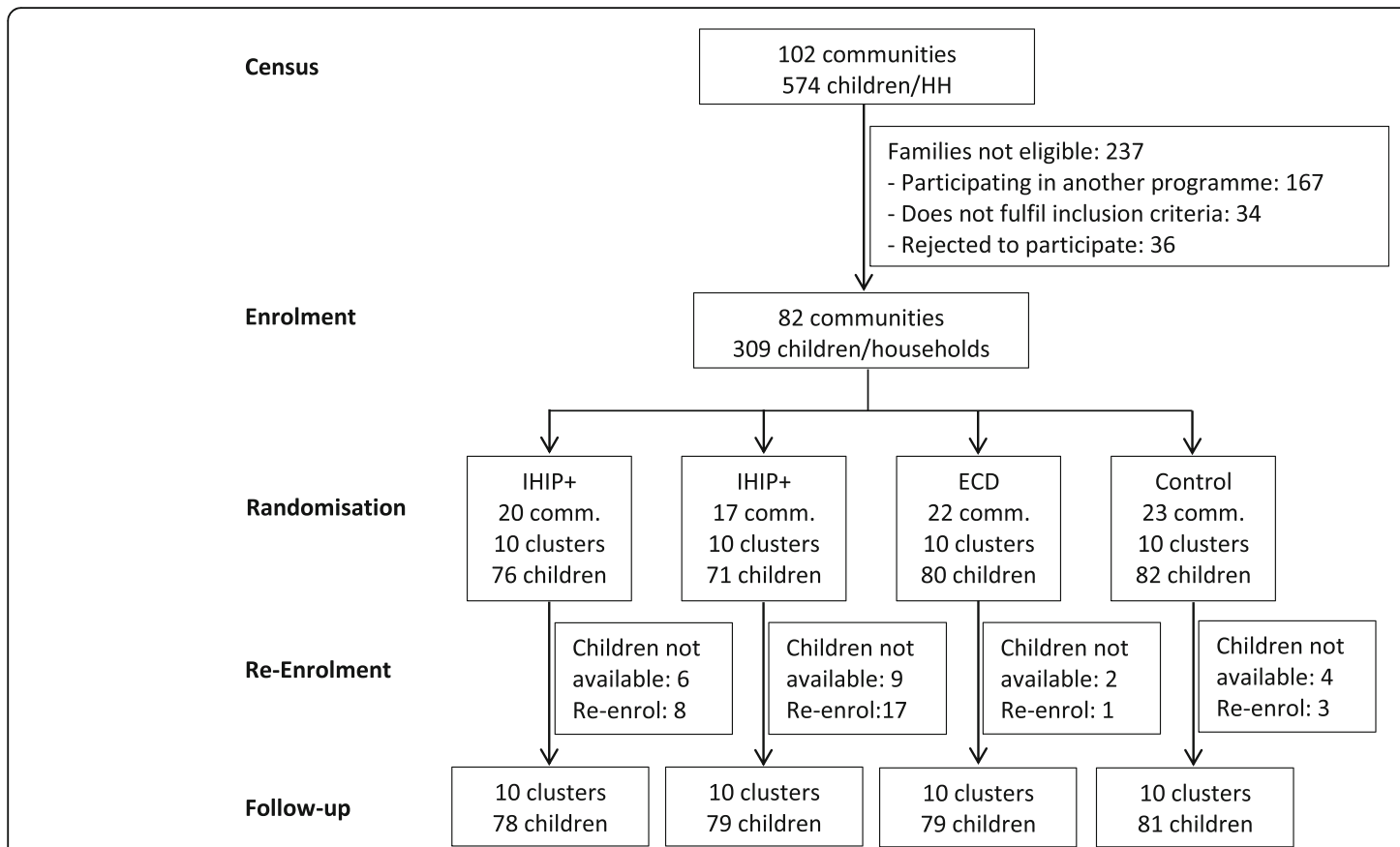

Fig. 1 Flow diagram of a cluster-randomised controlled trial in rural Andean Peru

Table 1 Demographic and household characteristics of households in rural Andean Peru

\begin{tabular}{|c|c|c|c|c|c|c|c|c|}
\hline & \multicolumn{2}{|c|}{$\mathrm{IHIP+}$} & \multicolumn{2}{|c|}{$\mathbb{I H I P}$} & \multicolumn{2}{|c|}{ ECD } & \multicolumn{2}{|c|}{ Control } \\
\hline & $\mathrm{N}$ & Mean (SD) or \% (N) & $\mathrm{N}$ & Mean (SD) or \% (N) & $\bar{N}$ & Mean (SD) or \% (N) & $\mathrm{N}$ & Mean (SD) or \% (N) \\
\hline Demographic characteristics & 78 & & 79 & & 79 & & 81 & \\
\hline Number of inhabitants per household & & $4.9(1.5)$ & & $5.1(1.7)$ & & $4.8(1.4)$ & & $5.0(1.5)$ \\
\hline Child sex (female) & & $43.6 \%(34)$ & & $50.6 \%(40)$ & & $53.2 \%(42)$ & & $55.6 \%(45)$ \\
\hline Child age (years) $^{\mathrm{a}}$ & & $1.5(0.5)$ & & $1.5(0.5)$ & & $1.7(0.5)$ & & $1.7(0.5)$ \\
\hline Child $<1$ year $^{a}$ & & $20.5 \%(16)$ & & $20.3 \%(16)$ & & $10.1 \%(8)$ & & $9.9 \%(8)$ \\
\hline Age of caretaker (years) & & $27.3(7.1)$ & & $28.4(7.4)$ & & $27.2(6.6)$ & & $28.0(6.9)$ \\
\hline Maternal education & 78 & & 79 & & 79 & & 81 & \\
\hline None & & $6.4 \%(5)$ & & $2.5 \%(2)$ & & $5.1 \%(4)$ & & $7.4 \%(6)$ \\
\hline Primary level completed & & $30.8 \%(24)$ & & $32.9 \%(26)$ & & $27.9 \%(22)$ & & $23.5 \%(19)$ \\
\hline Secondary level completed & & $21.8 \%(17)$ & & $6.3 \%(5)$ & & $17.7 \%(14)$ & & $8.6 \%(7)$ \\
\hline Higher degrees completed & & $0 \%(0)$ & & $3.8 \%(3)$ & & $5.1 \%(4)$ & & $1.2 \%(1)$ \\
\hline Years of schooling ${ }^{b}$ & & $6.1(3.5)$ & & $6.1(3.3)$ & & $6.9(3.5)$ & & $5.6(3.2)$ \\
\hline Household characteristics & 78 & & 79 & & 79 & & 81 & \\
\hline Adobe wall type & & $89.7 \%(70)$ & & $92.4 \%(73)$ & & $93.7 \%(74)$ & & $100 \%(81)$ \\
\hline Earthen floor type & & $83.3 \%(65)$ & & $89.9 \%(71)$ & & $94.9 \%(75)$ & & $93.8 \%(76)$ \\
\hline Roof tile type & & $82.1 \%(64)$ & & $87.3 \%(69)$ & & $86.1 \%(68)$ & & $95.1 \%(77)$ \\
\hline Household with latrines & & $55.1 \%(43)$ & & $53.2 \%(42)$ & & $58.2 \%(46)$ & & $61.7 \%(50)$ \\
\hline Piped water supply & & $97.4 \%(76)$ & & $98.7 \%(78)$ & & $100 \%(79)$ & & $98.8 \%(80)$ \\
\hline Electricity & & $65.4 \%(51)$ & & $82.3 \%(65)$ & & $77.2 \%(61)$ & & $85.2 \%(69)$ \\
\hline
\end{tabular}

\footnotetext{
${ }^{a}$ Age calculated for the start of follow-up (April $1^{\text {st }} 2016$ )
}

${ }^{\mathrm{b}}$ For higher degrees, we assumed: Non-university education not completed (12.5 years), non-university education completed (14 years), university education not completed ( 13.5 years) and university education completed ( 16 years) 


\section{Demographic and household characteristics}

The four arms were balanced in most of the domains (Table 1). Mothers from the four arms were of similar mean age, had similar levels of primary education and years of schooling. The majority of household had adobe walls, earthen floors, tiled roofs, and piped water system.
We observed differences among trial arms in the proportion of children below 1 year. This imbalance disappears comparing IHIP versus no-IHIP or ECD versus no-ECD arms. We also observed imbalance in the proportion of households with electricity. Although living in villages having an electricity connection was a randomisation

Table 2 Children's health status and vaccination coverage in rural Andean Peru

\begin{tabular}{|c|c|c|c|c|c|c|c|c|}
\hline & \multicolumn{2}{|c|}{$\mathrm{HIP+}$} & \multicolumn{2}{|c|}{$\mathrm{HIP}$} & \multicolumn{2}{|c|}{ ECD } & \multicolumn{2}{|c|}{ Control } \\
\hline & $\bar{N}$ & $\begin{array}{l}\text { Mean }(\mathrm{SD}) \\
\text { or } \%(\mathrm{~N})\end{array}$ & $\bar{N}$ & $\begin{array}{l}\text { Mean }(\mathrm{SD}) \\
\text { or \% }(\mathrm{N})\end{array}$ & $\bar{N}$ & $\begin{array}{l}\text { Mean }(\mathrm{SD}) \\
\text { or } \%(\mathrm{~N})\end{array}$ & $\bar{N}$ & $\begin{array}{l}\text { Mean (SD) } \\
\text { or \% (N) }\end{array}$ \\
\hline Anthropometrics $^{\mathrm{a}}$ & 78 & & 79 & & 79 & & 81 & \\
\hline Height-for-age, Z-values & 64 & $-1.3(1.1)$ & 50 & $-1.0(0.9)$ & 64 & $-1.5(1.1)$ & 61 & $-1.4(0.8)$ \\
\hline Stunting & 64 & $17.2 \%(11)$ & 50 & $9.8 \%(5)$ & 64 & $36.9 \%(24)$ & 61 & $18.0 \%(11)$ \\
\hline Weight-for-age, Z-scores & 64 & $-0.4(1.0)$ & 51 & $-0.1(0.8)$ & 65 & $-0.6(0.9)$ & 61 & $-0.5(0.9)$ \\
\hline Underweight & 64 & $6.3 \%(4)$ & 51 & $2.0 \%(1)$ & 65 & $10.8 \%(7)$ & 61 & $4.9 \%(3)$ \\
\hline Children's health status & 78 & & 79 & & 79 & & 81 & \\
\hline Weight at birth & & $3.1(0.6)$ & & $3(0.5)$ & & $3.1(0.5)$ & & $3.1(0.4)$ \\
\hline Diarrhoea, two-weeks prevalence & & $18.4 \%(14)$ & & $22.8 \%(18)$ & & $19 \%(15)$ & & $26.3 \%(21)$ \\
\hline Fever, two-weeks prevalence & & $21.8 \%(17)$ & & $21.5 \%(17)$ & & $25.3 \%(20)$ & & $23.5 \%(19)$ \\
\hline Cough, two-weeks prevalence & & $35.1 \%(27)$ & & $31.7 \%(25)$ & & $39.2 \%(31)$ & & $29.1 \%(23)$ \\
\hline Children with no health coverage & & $10.3 \%(8)$ & & $10.1 \%(8)$ & & $5.1 \%(4)$ & & $1.2 \%(1)$ \\
\hline Children's vaccination & 78 & & 79 & & 79 & & 81 & \\
\hline Tuberculosis (BCG) & 77 & $89.6 \%(69)$ & & $91.1 \%(72)$ & & $94.9 \%(75)$ & & $95.1 \%(77)$ \\
\hline Measles & 77 & $50.7 \%(39)$ & 78 & $60.3 \%(47)$ & 77 & $67.5 \%(52)$ & & $64.2 \%(52)$ \\
\hline \multicolumn{9}{|c|}{ Diphtheria, convulsive cough and tetanus (DTP) } \\
\hline 1st dose & 77 & $96.1 \%(74)$ & & $94.9 \%(75)$ & & $98.7 \%(78)$ & & $95.1 \%(77)$ \\
\hline 2nd dose & 73 & $90.4 \%(66)$ & 77 & $89.6 \%(69)$ & & $97.5 \%(77)$ & 79 & $93.7 \%(74)$ \\
\hline $3 r d$ dose & 64 & $87.5 \%(56)$ & 69 & $79.7 \%(55)$ & 72 & $93.1 \%(67)$ & 73 & $82.2 \%(60)$ \\
\hline \multicolumn{9}{|l|}{ Polio (OPV) } \\
\hline 1st dose & 77 & $96.1 \%(74)$ & & $96.2 \%(76)$ & & $98.7 \%(78)$ & & $96.3 \%(78)$ \\
\hline 2nd dose & 73 & $89.0 \%(65)$ & 77 & $90.9 \%(70)$ & & $97.5 \%(77)$ & 79 & $93.7 \%(74)$ \\
\hline 3rd dose & 64 & $78.1 \%(50)$ & 69 & $79.7 \%(55)$ & 72 & $90.3 \%(65)$ & 73 & $75.3 \%(55)$ \\
\hline Influenza & 77 & $62.3 \%(48)$ & & $63.3 \%(50)$ & & $81.0 \%(64)$ & & $69.1 \%(56)$ \\
\hline Hepatitis B & 77 & $62.3 \%(48)$ & & $54.4 \%(43)$ & & $79.8 \%(63)$ & & $69.1 \%(56)$ \\
\hline Recommended vaccines 6-11 months & 23 & & 28 & & 24 & & 15 & \\
\hline All vaccines $^{d}$ & & $69.6 \%(16)$ & & $60.7 \%(17)$ & & $87.5 \%(21)$ & & $40 \%(6)$ \\
\hline No vaccines & & $0 \%(0)$ & & $7.1 \%(2)$ & & $0 \%(0)$ & & $0 \%(0)$ \\
\hline Recommended vaccines $12-24$ months & 41 & & 41 & & 48 & & 58 & \\
\hline All vaccines ${ }^{e}$ & & $68.3 \%(28)$ & & $70.7 \%(29)$ & 46 & $84.8 \%(39)$ & & $70.7 \%(41)$ \\
\hline No vaccines & & $2.4 \%(1)$ & & $4.9 \%(2)$ & & $2.1 \%(1)$ & & $0 \%(0)$ \\
\hline Portable pulse oximetry assessment ${ }^{f}$ & 64 & & 59 & & 63 & & 68 & \\
\hline Oxygen saturation $\left(\mathrm{SpO}_{2}\right)$ & & $93.5(2.8)$ & & $94.2(2.5)$ & & $93.8(3.8)$ & & $93.8(2.8)$ \\
\hline Respiratory rate per/min. & & $27.7(3.7)$ & & $26.4(3.0)$ & & $27.2(2.7)$ & & $27.3(3.1)$ \\
\hline
\end{tabular}

'As estimated on $15^{\text {th }}$ December 2015 ( \pm 31 days). If several estimates within the range were available, the one closest to $15^{\text {th }}$ of December was selected

bDPT vaccination: $1^{\text {st }}$ dose: 2 month; $2^{\text {nd }}$ dose: 4 month; and $3^{\text {rd }}$ dose: 6 month

c Polio vaccination: $1^{\text {st }}$ dose: 2 month; $2^{\text {nd }}$ dose: 4 month; and $3^{\text {rd }}$ dose: 6 month

${ }^{d}$ It includes BCG (one dose), DTP (three doses) and OPV (three doses)

e It includes BCG (one dose), DTP (three doses), OPV (three doses) and measles (one dose)

${ }^{f}$ Results from children with no observable danger signs, fever, cough and difficulty to breath at the time of the assessment 
constraint it did not ensure balance at household level (in villages with connection the proportion of households with electricity varied from 50 to $100 \%$ ).

\section{Health characteristics}

Children in all arms had similar weight at birth. Imbalance was observed in the prevalence of stunting, with the highest proportion in the ECD arm (36.9\%). The two-week diarrhoea prevalence was balanced between arms, as was the two-week prevalence of cough and fever. However, we did observed differences between the health insurance coverage between arms, with the highest lack of coverage in the IHIP + $(10.3 \%)$ and the lowest in the control arm (1.3\%). Vaccination coverage, varied between arms (Table 2). The highest complete doses of vaccines for children aged between 6 and 11 months were in the ECD, and the lowest in the control arm (40\%). These percentages change when we look at children between aged 12-24 months, where coverage levels in the ECD arm increase up to $70 \%$ and the four arms are balanced. $\mathrm{SpO}_{2}$ and respiratory rate levels were similar in all arms (Table 2).

\section{Household microbial contamination}

We obtained 314 water samples. Some 52.9\% $(N=166)$ tested positive for thermo-tolerant bacteria. The number of positives and the occurrence of E.coli and Enterobacter were evenly distributed between arms. We observed imbalances in the occurrence of Klebsiella and Citrobacter, although the number of cases were small (Table 3).

\section{Household and personal air pollution}

We measured indoor $\mathrm{PM}_{2.5}$ and $\mathrm{CO}$ concentrations stationary from the kitchen environments and personal exposure ( $\mathrm{CO}$ only) before the installation of the ICS. Data was collected from 33 households. The average household $\mathrm{PM}_{2.5}$ and $\mathrm{CO}$ concentration were $213 \mu \mathrm{g} / \mathrm{m}^{3}$ $(\mathrm{SD}=166.1)$ and $4.8 \mathrm{ppm}(\mathrm{SD}=3.7)$ respectively (Table 4$)$.

\section{Early child development assessment}

Child psychomotor and cognitive development indicators of 305 study children indicated similar performance in all developmental domains across arms (Fig. 2).

\section{Discussion}

We present the baseline results of a cluster-randomised trial evaluating an integrated home-environmental intervention package and an ECD programme to improve diarrhoea, ARI and developmental outcomes in children under 36 months of age living in resourcelimited rural Andean Peru. This trial uses a robust $2 \times 2$ factorial design that allows the assessment of two interventions in a single study without increasing sample size [48]. For the ECD intervention, we implemented one component of Peru's national ECD programme (PNCM).

The trial included 317 rural families living in 82 communities from two Peruvian provinces. Baseline results indicate the trial arms are balanced with respect to most baseline characteristics, but given the limited number of clusters and the amount of characteristics presented, we also found a few imbalances. Imbalances observed will be considered in the primary trial analysis comparing each intervention separately with its counterfactual, i.e. IHIP versus no-IHIP to assess the impact of the IHIP intervention, and ECD versus no-ECD arms to evaluate the effects of the ECD intervention. While the ECD performance measurements at baseline appear to be inaccurately high, results are robust and show no difference in ECD status between trial arms. We also found that households across all arms share a notable burden of household environmental risks. Microbial contamination of drinking water does not comply with the Peruvian and WHO standards of zero viable coliforms in potable water samples $[49,50]$. Indoor and personal 24-h CO air pollution measurements in our study meet WHO guidelines [51], but kitchen $\mathrm{PM}_{2.5}$ levels exceed the threshold of $25 \mu \mathrm{g} / \mathrm{m}^{3}$ recommended by the WHO $\left(213 \mu \mathrm{g} / \mathrm{m}^{3}\right)$ [52].

There is an important need for implementing effective national ECD programmes to address the burden of poor development in early childhood. Experiences demonstrate that implementing ECD programmes in low- and middle-income countries is feasible and cost-effective [53]. Our trial offers an ideal opportunity to generate strong evidence regarding the PNCM programme's efficacy and support the Peruvian national government in its expansion on a wider scale.

Table 3 Thermo-tolerant bacteria from household drinking water samples in rural Andean Peru

\begin{tabular}{|c|c|c|c|c|c|c|c|c|c|c|}
\hline & \multicolumn{2}{|c|}{$\mathrm{HIP+}$} & \multicolumn{2}{|c|}{ IHIP } & \multicolumn{2}{|c|}{ ECD } & \multicolumn{2}{|c|}{ Control } & \multicolumn{2}{|c|}{ Total } \\
\hline & $\mathrm{N}$ & $\%(\mathrm{~N})$ & $\mathrm{N}$ & $\%(\mathrm{~N})$ & $\mathrm{N}$ & $\%(\mathrm{~N})$ & $\mathrm{N}$ & $\%(\mathrm{~N})$ & $\mathrm{N}$ & $\%(\mathrm{~N})$ \\
\hline & 38 & & 37 & & 43 & & 48 & & 166 & \\
\hline E.coli & & $71.1 \%$ (27) & & $73.0 \%(27)$ & & $65.1 \%(28)$ & & $72.9 \%(35)$ & & $70.5 \%(117)$ \\
\hline Klebsiella & & $10.5 \%(4)$ & & $8.1 \%$ (3) & & $20.9 \%$ (9) & & $18.8(9)$ & & $15.1 \%(25)$ \\
\hline Enterobacter & & $10.5 \%(4)$ & & $10.8 \%(4)$ & & $9.3 \%(4)$ & & $8.3 \%(4)$ & & $9.7 \%(16)$ \\
\hline Citrobacter & & $7.9 \%(3)$ & & $8.1 \%(3)$ & & $4.7 \%(2)$ & & $0 \%(0)$ & & $4.8 \%(8)$ \\
\hline
\end{tabular}


Table 4 HAP measurements at baseline in rural Andean Peru

\begin{tabular}{lcccc}
\hline & $\mathrm{N}$ & Mean $(95 \% \mathrm{IC})$ & Median $(95 \% \mathrm{IC})$ & Geometric mean $(95 \% \mathrm{IC})$ \\
\hline $\begin{array}{l}\text { Kitchen } \\
\mathrm{PM}_{2.5}\left(\mathrm{\mu g} / \mathrm{m}^{3}\right)\end{array}$ & 33 & $213(154.9-271.2)$ & $46.5(23.5-64.6)$ & $48.1(37.5-61.7)$ \\
$\quad \mathrm{CO}(\mathrm{ppm})$ & & $4.8(3.5-6.2)$ & $1.1(0.7-1.7)$ & $1.3(1.0-1.7)$ \\
$\begin{array}{l}\text { Personal } \\
\text { CO }(\mathrm{ppm})\end{array}$ & 33 & & $0(0-0)$ & $2.4(1.9-3.1)$ \\
\hline
\end{tabular}

The use of active surveillance in this trial will maximise sensitivity while passive surveillance increases the likelihood that true cases will be diagnosed, increasing specificity [54]. To synchronise ARI diagnosis with new national guidelines (stipulated by the MINSA) and address potential limitations of passive ARI surveillance, we equipped all the health centres in our working area with PPOs. Both, health and project field staff were trained, monitored and supervised monthly in the use of PPOs to assess ARI cases equally. PPOs have been underutilised in resource-limited health care settings for a variety of reasons, including high cost, inadequate supply and lack of training [55]. Our design overcomes these limitations and furthers the research on the usefulness and effectiveness of PPOs for ARI case assessments. In addition, PPOs have been shown to be optimal tools for identifying children with hypoxemia, an indicator for severe respiratory diseases [56]. Previous research indicated that the reference $\mathrm{SpO}_{2}$ thresholds for hypoxemia are lower at high altitudes in comparison to those at sea level [57]. A median $\mathrm{SpO}_{2}$ hypoxemia threshold of $96 \%$ for children below 5 years living at 2500 m.a.s.l has been proposed [58]. Our $\mathrm{SpO}_{2}$ results in healthy children living between 2250 and 3900 m.a.s.l are lower than the suggested threshold. Hence, considering specific $\mathrm{SpO}_{2}$ hypoxemia thresholds for children living in high altitudes becomes a challenge. Our systematic health data collection using PPOs may further pave the way for assessing $\mathrm{SpO}_{2}$ hypoxemia threshold values at high altitude settings for children with and without related ARI symptoms [59].

Little attention has been paid to users' perspectives and preferences in the design of ICS interventions in the past [60]. We conducted a community consultation to select an ICS model that was both locally accepted and efficient. According to recent evidence, those who participate in community consultations to select ICS models have a higher likelihood of increasing ICS use over time [61].

Our study has some limitations. Because of the nature of the trial design, interventions could not be blinded. The use of tablet-based technologies to measure pulse oximetry was a challenge for both health centre and field staff. We trained the health centre personnel on the correct use and benefits of introducing PPOs in their

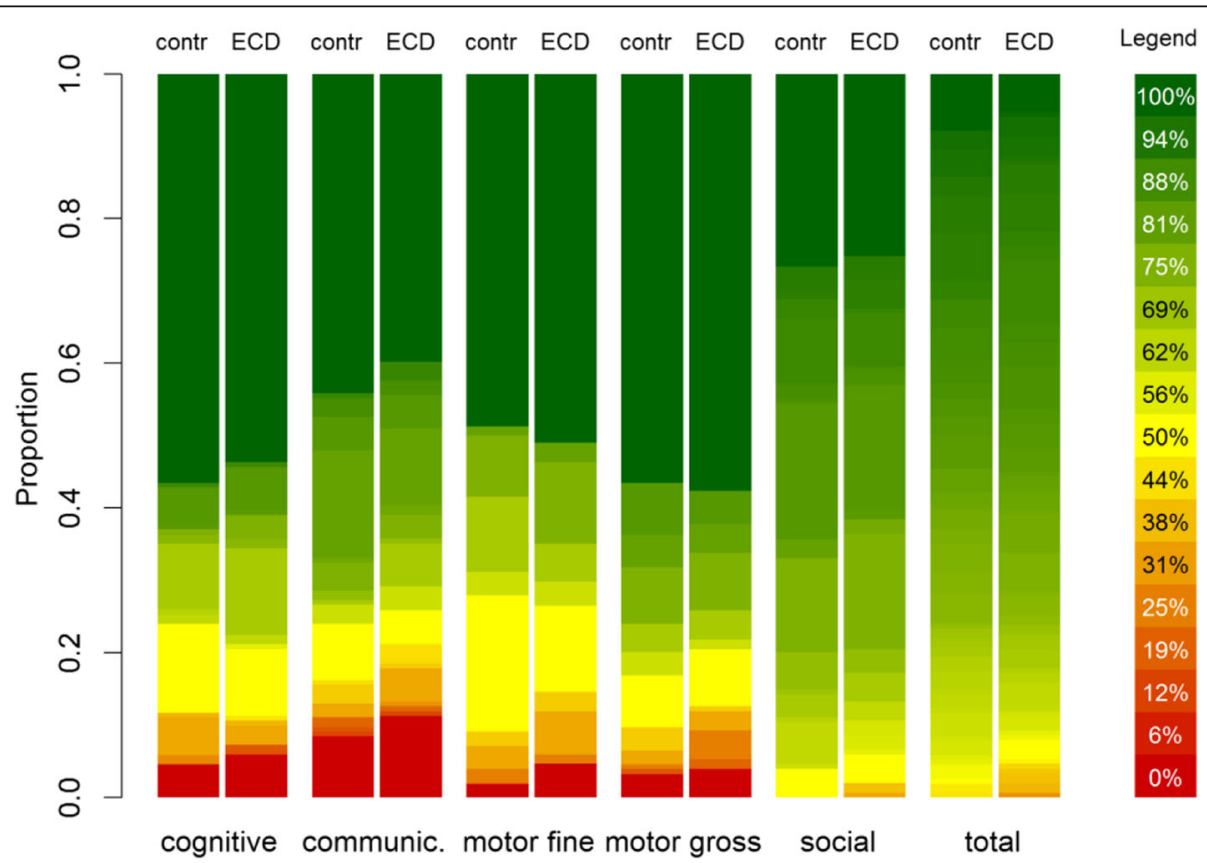

Fig. 2 Proportion of tasks completed for all early child developmental domains 
daily work in two group sessions. However, due to frequent changes of the personnel in health centre, we had to retrain new staff individually on-site on a monthly basis. Baseline ECD evaluation and the age-specific assessment tools were not as straightforward to apply as we had experienced previously [25]. Despite the assertion from the PNCM programme experts that novices could also use the ESDI tool, we found that the lack of familiarity and experience among the field staff consistently produced unusually high scores in all individuals (at baseline). However, in the context of this baseline assessment, the screening was conducted to assess the relative ECD status between study arms as opposed to estimate absolute differences in ECD psychomotor and cognitive indicators. Hence, overall high scores do not invalidate our conclusion that randomisation was successful given that study arms had similar ECD levels at baseline. To diminish any further potential bias at the end of study, we will apply both the ESDI and BSID tools.

Despite the limitations, we believe that the IHIP-2 trial will generate needed evidence on the potential synergistic benefits of combining ECD and environmental health interventions. We actively sought to involve national and governmental actors (i.e. PNCM, SENCICO, MINSA) in developing our interventions and throughout the study to foster sustainability and reinforce collaborative engagements in the future.

\section{Conclusion}

In this paper, we present the baseline results of a factorial cluster-randomised trial evaluating an integrated home-environmental intervention package and an early child development intervention in children under 36 months of age living in rural Andean Peru. The trial arms were balanced with respect to most baseline characteristics, air and water contamination and child's developmental status. Baseline results determine that the trial's randomisation was successful and study arms are comparable for analysis at the end of study. The results of this trial will yield valuable information for assessing the synergic, rational and cost-effective benefits of the combination of home-based interventions.

\section{Supplementary information}

Supplementary information accompanies this paper at https://doi.org/10. 1186/s12874-020-00950-y.

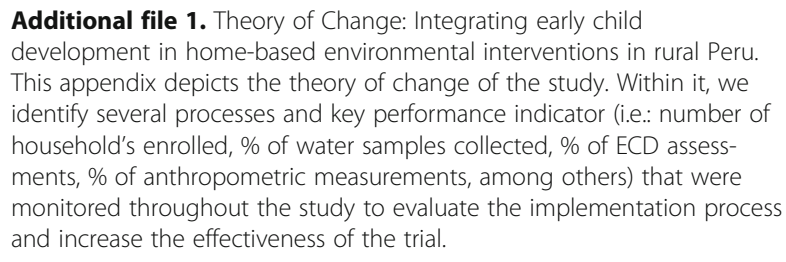

\section{Abbreviations}

AAF: Acompañamiento a Familias; ARI: Acute respiratory infections: BSID: Bayley Scales of Infant and Toddler Development tool; CBT: Capacity building team; CO: Carbon monoxide; ECD: Early child development; ESDI: Peruvian infant development scale tool; EV: Environmental team; FW: Fieldworker team; HAP: Household air pollution; ICS: Improved cookstoves; IHIP: Integrated home-based intervention package; MINSA: Peruvian Ministry of Health; MF: Mother facilitators; PM $_{2.5}$ : fine particulate matter; PNCM: Program Nacional Cuna Mas; PPO: Portable pulse oximeters; PS: Passive surveillance team; SENCICO: Peruvian national industrial certification authority; $\mathrm{SpO}_{2}$ : Oxygen saturation in blood; TA: Technical assistant team; WHO: World Health Organization

\section{Acknowledgements}

The authors would like to express their appreciation to the study families for their kind participation, the San Marcos RedSalud-IV and local authorities for their continuous support. We also express our gratitude to the field coordinators, especially to Mrs. Angelica Fernandez and Ms. Maria Luisa Huaylinos, for their unfailing support. The work developing the mHealth app was supported by Jia Zhang who performed data quality analysis and Matthias Hüser who coded the app.

\section{Authors' contributions}

DM and SH designed the study; DM, SH and WK obtained the funding; $\mathrm{SH}$, NNM and HV collected data; SH, NNM, HV and MO were in charge of implementing interventions; $\mathrm{JH}$ provided with essential statistical advice and with HV generated the randomisation for the study. SH, HV, NNM, JH and WK analysed and interpreted the data; $\mathrm{SH}$ wrote the first draft manuscript; $\mathrm{DM}, \mathrm{HV}, \mathrm{NNM}, J \mathrm{H}, \mathrm{WK}$ and $\mathrm{MO}$ interpreted the data, performed critical revisions of the manuscript and contributed to the writing; $\mathrm{SH}, \mathrm{DM}, \mathrm{HV}, \mathrm{MO}$, WK provided administrative, technical and material support; SH, HV, NNM, and DM, coordinated and supervised the study. All authors have read and approved the manuscript.

\section{Funding}

This study received financial support of the UBS Optimus Foundation and the Grand Challenges, Canada. The mobile health monitoring was supported through ETH Global seed funding. The sponsors had no involvement in the study design, data collection and analysis, writing or the decision to submit the article for publication.

\section{Availability of data and materials}

The datasets used and/or analysed during the current study are available from the corresponding author on reasonable request.

\section{Ethics approval and consent to participate}

The trial was retrospectively registered on 15th January 2018 (Trial registry: ISRCTN-26548981). The study was approved by the Cajamarca Regional Health Authority and the Universidad Peruana Cayetano Heredia (UPCH) (Ref. 268-12-15). Community leaders and local authorities from the study area signed a collaborative agreement with the UPCH before study implementation. Families who agreed to participate in the study provided a written informed consent. No incentives were given to foster participation.

Consent for publication

Not applicable

\section{Competing interests}

The authors declare that they have no competing interests.

\section{Author details}

'Department of Epidemiology \& Public Health, Swiss Tropical and Public Health Institute, Basel, Switzerland. ${ }^{2}$ University of Basel, Basel, Switzerland. ${ }^{3}$ School of Public Health and Administration, Universidad Peruana Cayetano Heredia, Lima, Peru. ${ }^{4}$ Department of Health Sciences and Technology, ETH Zürich, Zürich, Switzerland. ${ }^{5}$ Programa Nacional CUNA MAS, Lima, Peru. 
Received: 5 October 2018 Accepted: 6 March 2020 Published online: 02 April 2020

\section{References}

1. Lakshmi A, Jamal S. Assessing vulnerability of women to indoor air pollution. Res J Environ Earth Scie. 2012;4(11):982-9.

2. Global Burden of Disease Study 2017 Risk Factor Collaborators. Global, regional, and national comparative risk assessment of 84 behavioural, environmental and occupational, and metabolic risks or clusters of risks for 195 countries and territories, 1990-2017: a systematic analysis for the Global Burden of Disease Study 2017. Lancet. 2018:392(10159):1923-94.

3. Bonjour S, Adair-Rohani H, Wolf J, Bruce NG, Mehta S, Prüss-Ustün A, et al. Solid fuel use for household cooking: country and regional estimates for 1980-2010. Environ Health Perspect. 2013;121(7):784-90.

4. World Health Organization, United Nations Children's Funds. Progress on Drinking Water and Sanitation. Geneva: World Health Organization, UNICEF; 2014.

5. Smith KR, Bruce N, Balakrishnan K, Adair-Rohani H, Balmes J, Chafe Z, et al. Millions dead: how do we know and what does it mean? Methods used in the comparative risk assessment of household air pollution. Annu Rev Public Health. 2014;35:185-206.

6. Lim SS, Vos T, Flaxman AD, Danaei G, Shibuya K, Adair-Rohani H, et al. A comparative risk assessment of burden of disease and injury attributable to 67 risk factors and risk factor clusters in 21 regions, 1990-2010: a systematic analysis for the global burden of disease study 2010. Lancet. 2012;380(9859): 2224-60.

7. Darvesh N, Das JK, Vaivada T, Gaffey MF, Rasanathan K, Bhutta ZA, et al. Water, sanitation and hygiene interventions for acute childhood diarrhea: a systematic review to provide estimates for the lives saved tool. BMC Public Health. 2017;17(Suppl 4):776

8. Cohen A, Colford JM. Effects of boiling drinking water on diarrhea and pathogen-specific infections in low- and middle-income countries: a systematic review and meta-analysis. Am J Trop Med Hyg. 2017;97(5):1362-77.

9. Balmes JR, Eisen EA. Household Air Pollution and Chronic Obstructive Pulmonary Disease. "A Riddle, Wrapped in a Mystery, Inside an Enigma". Am J Respir Crit Care Med. 2018;197(5):547-9.

10. Balmes JR. Household air pollution from domestic combustion of solid fuels and health. J Allergy Clin Immunol. 2019;143(6):1979-87.

11. Dangour AD, Watson L, Cumming O, Boisson S, Che $Y$, Velleman $Y$, et al. Interventions to improve water quality and supply, sanitation and hygiene practices, and their effects on the nutritional status of children. Cochrane Database Syst Rev. 2013;8:CD009382.

12. Prüss-Ustün A, Wolf J, Bartram J, Clasen T, Cumming O, Freeman MC, et al. Burden of disease from inadequate water, sanitation and hygiene for selected adverse health outcomes: an updated analysis with a focus on low- and middle-income countries. Int J Hyg Environ Health. 2019;222(5): 765-77

13. World Health Organization. Mortality from household air pollution. Global Health Observatory $(\mathrm{GHO})$ data, World Health Organization; 2016. Available from: https://www.who.int/gho/phe/indoor_air_pollution/burden/en/.

14. Grantham-McGregor S, Cheung YB, Cueto S, Glewwe P, Richter L, Strupp B, et al. Developmental potential in the first 5 years for children in developing countries. Lancet. 2007;369(9555):60-70.

15. Walker SP, Wachs TD, Grantham-McGregor S, Black MM, Nelson CA, Huffman SL, et al. Inequality in early childhood: risk and protective factors for early child development. Lancet. 2011:378(9799):1325-38.

16. Ngure FM, Reid BM, Humphrey JH, Mbuya MN, Pelto G, Stoltzfus RJ. Water, sanitation, and hygiene (WASH), environmental enteropathy, nutrition, and early child development: making the links. Ann N Y Acad Sci. 2014;1308: $118-28$.

17. Lanphear BP. The impact of toxins on the developing brain. Annu Rev Public Health. 2015:36:211-30.

18. Siddiqi A, Irwin L, Hertzman C. Early child development : a powerful equalizer: final report for the World Health Organization's Commission on the Social Determinants of Health. Vancouver; 2007. (Human Early Learning Partnership \& Commission on Social Determinants of Health).

19. Maggi S, Irwin LJ, Siddiqi A, Hertzman C. The social determinants of early child development: an overview. J Paediatr Child Health. 2010;46(11):627-35.

20. Wolf J, Hunter PR, Freeman MC, Cumming O, Clasen T, Bartram J, et al. Impact of drinking water, sanitation and handwashing with soap on childhood diarrhoeal disease: updated meta-analysis and meta-regression. Tropical Med Int Health. 2018;23(5):508-25.

21. Hartinger SM, Commodore AA, Hattendorf J, Lanata CF, Gil Al, Verastegui H, et al. Chimney stoves modestly improved indoor air quality measurements compared with traditional open fire stoves: results from a small-scale intervention study in rural Peru. Indoor Air. 2013;23(4):342-52.

22. Thomas E, Wickramasinghe K, Mendis S, Roberts N, Foster C. Improved stove interventions to reduce household air pollution in low and middle income countries: a descriptive systematic review. BMC Public Health. 2015;15:650.

23. Smith KR, McCracken JP, Weber MW, Hubbard A, Jenny A, Thompson LM, et al. Effect of reduction in household air pollution on childhood pneumonia in Guatemala (RESPIRE): a randomised controlled trial. Lancet. 2011:378(9804):1717-26.

24. Petrovic O, Yousafzai A. Promoting Care for Child Development in community health services, a summary of the Pakistan early child development scale-up (PEDS) trial. Main findings, delivery strengths and the path forward. New York: United Nations Children's Fund; 2013.

25. Hartinger SM, Lanata CF, Hattendorf J, Wolf J, Gil Al, Obando MO, et al. Impact of a child stimulation intervention on early child development in rural Peru: a cluster randomised trial using a reciprocal control design. J Epidemiol Community Health. 2017:71(3):217-24.

26. Landrigan PJ, Fuller R, Acosta NJR, Adeyi O, Arnold R, Basu NN, et al. The Lancet Commission on pollution and health. Lancet. 2018;391(10119):462-512.

27. Vazir S, Engle P, Balakrishna N, Griffiths PL, Johnson SL, Creed-Kanashiro H, et al Cluster-randomized trial on complementary and responsive feeding education to caregivers found improved dietary intake, growth and development among rural Indian toddlers. Matern Child Nutr. 2013;9(1):99-117.

28. Hartinger SM, Lanata CF, Hattendorf J, Gil Al, Verastegui H, Ochoa T, et al. A community randomised controlled trial evaluating a home-based environmental intervention package of improved stoves, solar water disinfection and kitchen sinks in rural Peru: rationale, trial design and baseline findings. Contemp Clin Trials. 2011;32(6):864-73.

29. Hartinger SM, Lanata CF, Hattendorf J, Verastegui H, Gil Al, Wolf J, et al. Improving household air, drinking water and hygiene in rural Peru: a community-randomized-controlled trial of an integrated environmental home-based intervention package to improve child health. Int J Epidemiol. 2016;45(6):2089-99.

30. Clasen T, Smith KR. Let the "a" in WASH stand for air: integrating research and interventions to improve household air pollution (HAP) and water, sanitation and hygiene (WaSH) in low-income settings. Environ Health Perspect. 2019;127(2):25001.

31. Singla DR, Kumbakumba E, Aboud FE. Effects of a parenting intervention to address maternal psychological wellbeing and child development and growth in rural Uganda: a community-based, cluster randomised trial. Lancet Glob Health. 2015:3(8):e458-69.

32. Aboud FE, Singla DR, Nahil MI, Borisova I. Effectiveness of a parenting program in Bangladesh to address early childhood health, growth and development. Soc Sci Med. 2013;97:250-8.

33. Resultados Definitivos de los Censos Nacionales 2017 - Censos Nacionales 2017 [Internet]. [cited 2019 Mar 6]. Available from: http://censo2017.inei.gob. pe/resultados-definitivos-de-los-censos-nacionales-2017/.

34. Hayes RJ, Bennett S. Simple sample size calculation for cluster-randomized trials. Int J Epidemiol. 1999;28(2):319-26.

35. Moulton LH. Covariate-based constrained randomization of grouprandomized trials. Clin Trials. 2004;1(3):297-305.

36. Gil Al, Lanata CF, Hartinger SM, Mäusezahl D, Padilla B, Ochoa TJ, et al. Fecal contamination of food, water, hands, and kitchen utensils at the household level in rural areas of Peru. J Environ Health. 2014;76(6):102-6.

37. SENCICO. Reglamento para la evaluación y certificación de la cocina mejorada. Lima: SENCICO; 2011.

38. Programa Nacional Cuna Mas. Escala de desarrollo infantil. Manual de aplicación. Lima: MIDIS; 2016.

39. World Health Organization. The Treatment of Diarrhoea. A manual for physicians and other senior health workers. Geneva: World Health Organization; 2005.

40. World Health Organization. Handbook: IMCI integrated management of childhood. World Health Organization; 2005. https://apps.who.int/iris/ handle/10665/42939.

41. Lanata CF, Rudan I, Boschi-Pinto C, Tomaskovic L, Cherian T, Weber M, et al. Methodological and quality issues in epidemiological studies of acute lower respiratory infections in children in developing countries. Int J Epidemiol. 2004;33(6):1362-72. 
42. Petersen $\mathrm{CL}$, Gorges M, Dunsmuir D, Ansermino M, Dumont GA. Experience Report: Functional Programming of mHealth Applications. In: Proceedings of the 18th ACM SIGPLAN International Conference on Functional Programming [Internet]. New York, NY, USA: ACM; 2013 [cited 2019 Aug 14]. p. 357-62. (ICFP '13). Available from: http://doi.acm.org/10.1145/2500365.2500615.

43. Karlen W, Ansermino JM, Dumont G. Adaptive pulse segmentation and artifact detection in photoplethysmography for mobile applications. Conf Proc IEEE Eng Med Biol Soc. 2012;2012:3131-4.

44. Karlen W, Gan H, Chiu M, Dunsmuir D, Zhou G, Dumont GA, et al. Improving the accuracy and efficiency of respiratory rate measurements in children using mobile devices. PLoS One. 2014;9(6):e99266.

45. World Health Organization. WHO child growth standards: length/height-forage, weightforage, weight-for-length, weight-for-height and body mass index-for-age: methods and development. Geneva: World Health Organization; 2006.

46. OXFAM-DELAGUA. OXFAM-DELAGUA Water Testing Kit - Users Manual version 4.2, revised 2009. Marlborough: University of Surrey; 2009.

47. Bayley N. Bayley Scales of Infant and Toddler Development. (3rd ed.) San Antonio,TX. 3rd ed. San Antonio: The Psychological Corporation.; 2005.

48. Montgomery AA, Peters TJ, Little P. Design, analysis and presentation of factoria randomised controlled trials. BMC Med Res Methodol. 2003 Nov 24;3:26.

49. Ministerio de Salud. Decreto Supremo № 031-2010-SA- Reglamento de la calidad de Agua para Consumo Humano. Lima: Ministerio de Salud; 2010.

50. World Health Organization. Guidelines for Drinking Water Quality. 3rd Edition Volume 1 Recommendations. Geneva: World Health Organization; 2004.

51. World Health Organization. WHO guidelines for indoor air quality: selected pollutants. Copenhagen: World Health Organization; 2010.

52. World Health Organization. Occupational and Environmental Health Team. WHO Air quality guidelines for particulate matter, ozone, nitrogen dioxide and sulfur dioxide : global update 2005 : summary of risk assessment. Geneva: World Health Organization; 2006.

53. Richter LM, Daelmans B, Lombardi J, Heymann J, Boo FL, Behrman JR, et al. Investing in the foundation of sustainable development: pathways to scale up for early childhood development. Lancet. 2017;389(10064):103-18.

54. Hirve S, Singh SP, Kumar N, Banjara MR, Das P, Sundar S, et al. Effectiveness and feasibility of active and passive case detection in the visceral leishmaniasis elimination initiative in India, Bangladesh, and Nepal. Am J Trop Med Hyg. 2010;83(3):507-11.

55. Spence H, Baker K, Wharton-Smith A, Mucunguzi A, Matata L, Habte T, et al. Childhood pneumonia diagnostics: community health workers' and national stakeholders' differing perspectives of new and existing aids. Glob Health Action. 2017;10(1):1290340

56. Ginsburg AS, Delarosa J, Brunette W, Levari S, Sundt M, Larson C, et al. mPneumonia: development of an innovative mHealth application for diagnosing and treating childhood pneumonia and other childhood illnesses in low-resource settings. PLoS One. 2015;10(10):e0139625.

57. Schult S, Canelo-Aybar C. Oxygen saturation in healthy children aged 5 to 16 years residing in Huayllay, Peru at 4340 m. High Alt Med Biol. 2011;12(1): 89-92.

58. Rojas-Camayo J, Mejia CR, Callacondo D, Dawson JA, Posso M, Galvan CA, et al. Reference values for oxygen saturation from sea level to the highest human habitation in the Andes in acclimatised persons. Thorax. 2018;73(8): 776-8.

59. Tüshaus L, Moreo M, Zhang J, Hartinger SM, Mäusezahl D, Karlen W. Physiologically driven, altitude-adaptive model for the interpretation of pediatric oxygen saturation at altitudes above $2000 \mathrm{M}$ a.s.l. J Appl Physiol. 2019;127(3):847-57. https://doi.org/10.1152/japplphysiol.00478.2018.

60. Rehfuess EA, Puzzolo E, Stanistreet D, Pope D, Bruce NG. Enablers and barriers to large-scale uptake of improved solid fuel stoves: a systematic review. Environ Health Perspect. 2014;122(2):120-30.

61. Wolf J, Mäusezahl D, Verastegui H, Hartinger SM. Adoption of clean Cookstoves after improved solid fuel stove Programme exposure: a crosssectional study in three Peruvian Andean regions. Int J Environ Res Public Health 2017 8;14(7). https://doi.org/10.3390/ijerph14070745.

\section{Publisher's Note}

Springer Nature remains neutral with regard to jurisdictional claims in published maps and institutional affiliations.

\section{Ready to submit your research? Choose BMC and benefit from}

- fast, convenient online submission

- thorough peer review by experienced researchers in your field

- rapid publication on acceptance

- support for research data, including large and complex data types

- gold Open Access which fosters wider collaboration and increased citations

- maximum visibility for your research: over $100 \mathrm{M}$ website views per year

At $\mathrm{BMC}$, research is always in progress.

Learn more biomedcentral.com/submissions 